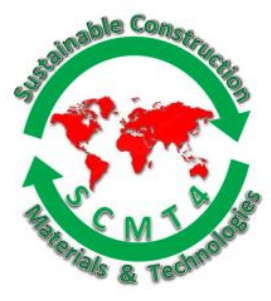

SCMT4

Las Vegas, USA, August 7-11, 2016

\title{
Mechanical Behavior of Recycled Concrete Aggregates (RCA) for Improved Sustainability of Reinforced Concrete Building Structures
}

\author{
Andres de la Rosa ${ }^{1 a}$, Mark Davis ${ }^{1 b}$, Brad Weldon², Yahya C. Kurama ${ }^{3}$, and Michael J. \\ McGinnis ${ }^{1 c}$ \\ ${ }^{1}$ Department of Civil Engineering, University of Texas at Tyler, USA \\ ${ }^{1 a}$ Email: <mdavis26@patriots.uttyler.edu>, ${ }^{1 b}$ Email: <adelarosa3@patriots.uttyler.edu>, ${ }^{1 c}$ Email: \\ <McGinnis@uttyler.edu> \\ ${ }^{2}$ Department of Civil Engineering, New Mexico State University, USA. Email: 〈bweldon@nmsu.edu> \\ ${ }^{3}$ Department of Civil \& Environmental Engineering \& Earth Sciences, University of Notre Dame, USA, \\ Email: <ykurama@nd.edu>.
}

\begin{abstract}
Concrete makes up a significant portion of both the existing (and aging) infrastructure of today and the planned infrastructure of tomorrow, with a corresponding large environmental impact. Rather than landfilling the concrete from obsolete applications, by crushing old concrete to make recycled concrete aggregates (RCA) for use in new concrete, the overall environmental impacts of concrete use can be reduced. Using RCA in new concrete does have issues that need to be addressed before full adoption can be realized. In particular, the strength and stiffness, workability, and durability of RCA concrete can all be different than those of natural aggregate concrete. Variability in RCA properties from source to source also must be addressed if guidelines for RCA use are to be created and adopted. The University of Norte Dame, the University of Texas at Tyler and New Mexico State University are currently participating in a research project designed to probe these issues. The current paper describes properties of RCA aggregates and of RCA concrete with RCA sourced from over thirty suppliers from four distinct areas of the United States (Northeast, South, Midwest and West regions), making this study the most geographically varied study of RCA known to the authors. Variability in aggregate properties and hardened concrete strength are addressed within the paper.
\end{abstract}

\section{INTRODUCTION}

Natural aggregate (NA) is a vital material that is required to meet the needs of society as well as providing the basic materials needed for construction. With concrete is the one most versatile building material on Earth and makes up a significant proportion of the past, present, and future infrastructure. It also possesses a major impact towards the environment. The idea of the conservation of natural aggregate has been largely ignored here in the United States despite the fact that coarse aggregates make up 40 to $50 \%$ of the concrete mix by volume (Mehta 2001) while cement makes up about $10 \%$. The possibilities of using recycled concrete from the existing infrastructure to either partially or fully replace the natural coarse aggregate in any future construction has the potential to improve sustainability of mostly 
reinforced concrete structures. To date, the use of recycled concrete aggregate (RCA) in the U.S. has been limited to non-structural applications such as sidewalks and roadways even though the quality of the material is generally significantly higher than is required in these applications. Recycling old concrete into material suitable for structural applications is likely to be cost-effective (Davis et al 2015). Despite the above benefits, only a small amount of RCA has been used in structural engineering projects in the U.S. The primary obstacles against their increased utilization are:

1. Little or no previous work exists to quantify the economic and environmental benefits of using RCA in structural applications.

2. Little or no previous works exists on the service and ultimate load performance of prestressed and non-prestressed concrete structures utilizing RCA from U.S. sources.

3. Even though RCA can readily pass the prescriptive requirements for coarse aggregates in structural concrete (ASTM C33 2008), the variability in material properties and quality needs to be quantified and incorporated into design.

4. As a result, no engineering guidelines/standards currently exists for the design and construction of reinforced concrete utilizing RCA.

The current project team is addressing each of these four issues. Davis et al. (2014) and Davis et al. (2015) are directed at quantifying environmental and economic aspects of RCA use. Knaack and Kurama (2013, 2015a, 2015b, and 2015c) address the second issue noted. The current paper targets the issue of variability of RCA properties and of concrete made with RCA. The project team collected more than 36 RCA samples from over 10 states representing four distinct geographical areas: the Northeastern US, the Southwestern US, the Midwest, and Texas. In the current paper, the properties of a subset of these are discussed. After a brief background of RCA is presented, material properties describing this RCA subset are discussed, and then the behavior of concrete mixes incorporating these RCA is presented.

\section{BACKGROUND}

Through previous research, RCA tends to have a decreased specific gravity, increased absorption, and increased L.A. abrasion loss since they contain the mortar paste from the original concrete. Because of the increased absorption, RCA concrete also has greater water demand (ACI 555 2001), which can be resolved by increasing the amount of mix water and/or by using water reducing admixtures and fly-ash. Generally, RCA concrete has smaller compressive strength, smaller stiffness, greater creep, and greater shrinkage. At full aggregate replacement, the majority of the previous research found concrete compressive strength losses ranging from $10 \%$ to $20 \%$. In comparison, the effect of RCA on the stiffness of concrete is greater with losses up to $33 \%$ at full replacement. An important limitation of the previous research has been the lack of quantitative evaluation of the variability in the RCA properties from different sources and the effect of this variability on the behavior of RCA concrete, with the objective to develop RCA qualification standards.

\section{SAMPLE DESCRIPTION}

Generally, most retailers of RCA do not sell it to a specific gradation or other quality and performance measures. Figure 1 gives an illustration of the RCA subset (of the 36 samples collected) presented in this paper as received by the project team. The figure gives a three letter code for each aggregate that is used to identify it throughout the remainder to deidentify RCA wholesalers, of this paper. 


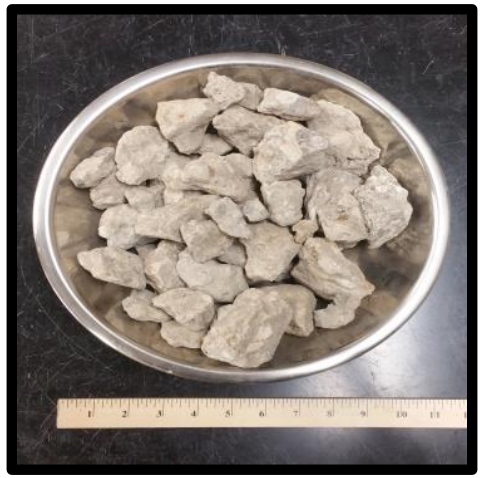

BCL - 3” (TX)

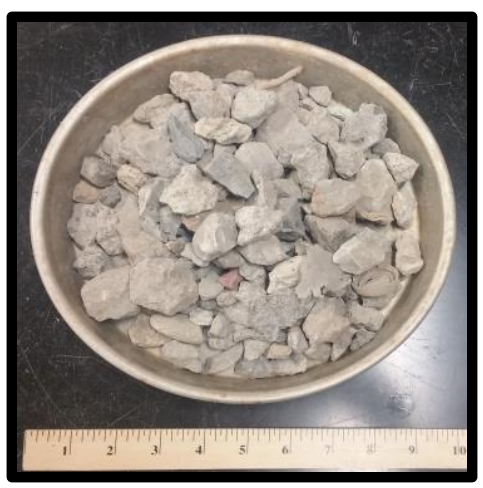

$\mathrm{CCN}-1.5 "$ to $0.375 "(\mathrm{PA})$

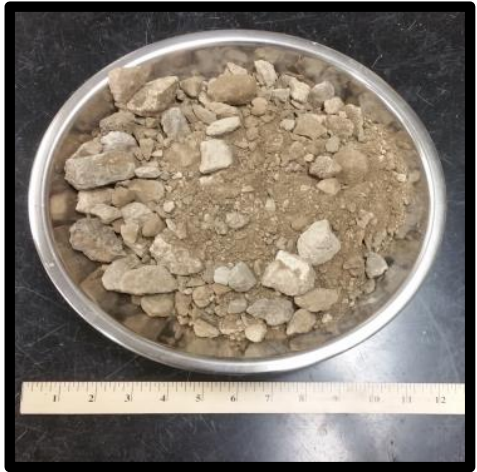

BCB - Base (TX)

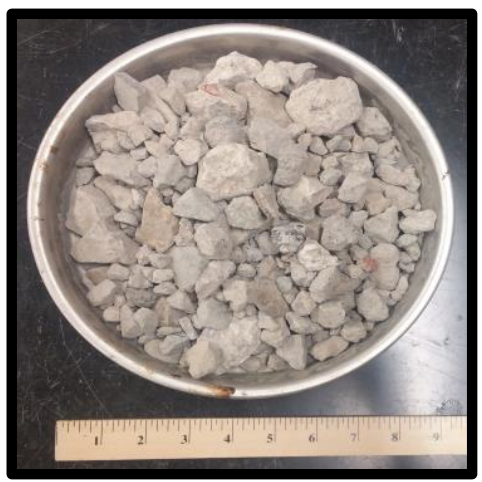

TIL - 1.5” Minus (NJ)

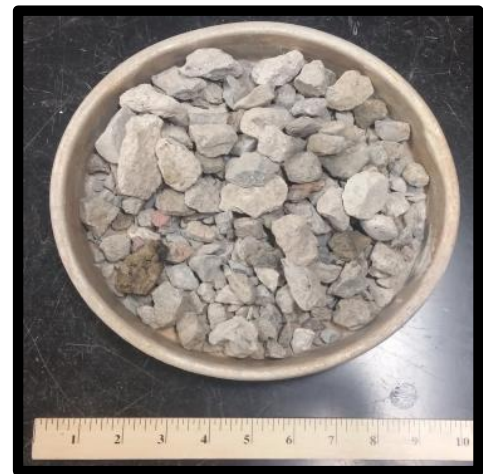

CCF - 1.5" Minus (PA)

Figure 1. Images of Samples

Coarse and fine aggregates should ideally be graded to ensure a workable and economical mix. Too much variability in aggregate size from mix to mix can affect the properties of concrete such as workability and strength.

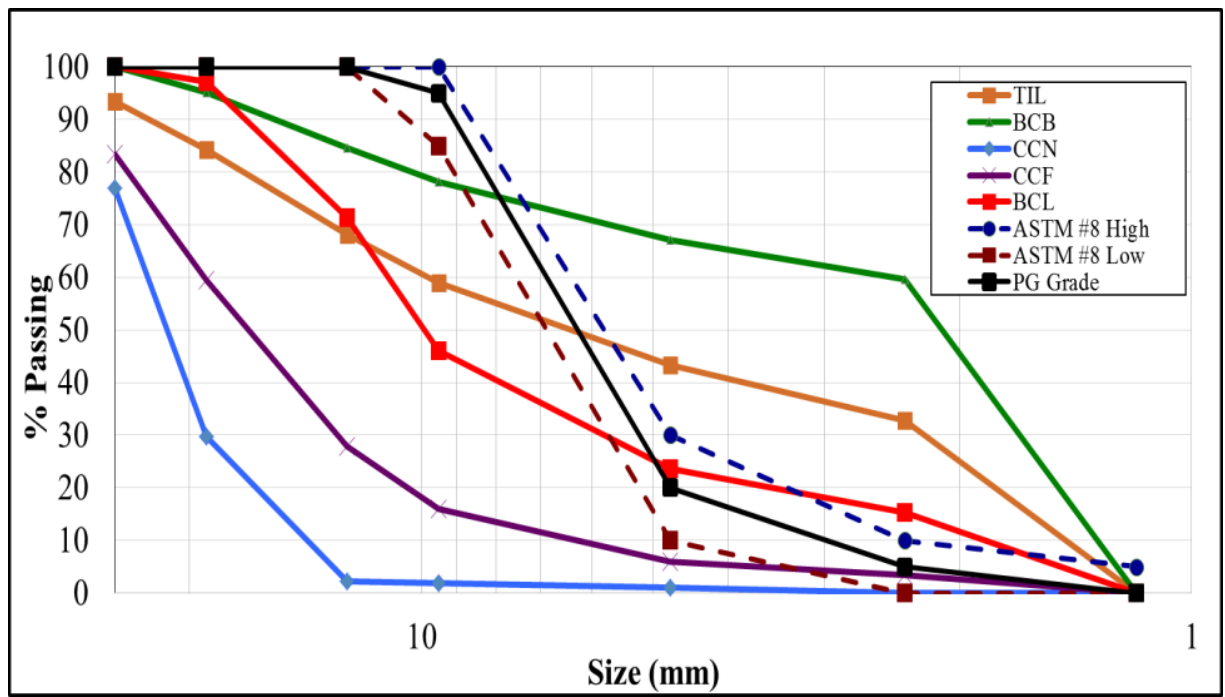

Figure 2. Gradations of ASTM C33 \#8, NA, and RCA 
Figure 2 displays the bounds of ASTM C33 \#8 as well as the gradations of project NA and RCA samples. There was significant variability in the gradation of RCA samples as received. The PG Grade line in the figure denotes the target gradation for the concrete mixes described later in this paper. For all of the concrete described herein, the RCA were graded to the PG Grade to ensure consistency. Table 1 shows several important physical properties characterizing the RCA subset. Specific Gravity (Relative Density) and Absorption were determined by following ASTM C127 (2005) (Coarse Aggregate). For the fine aggregate (sand), the Specific Gravity and Absorption were found using ASTM C128 (2005), with the test performed by an outside laboratory.

$\mathrm{D}_{\mathrm{RCA}}$ defines the percent (by weight) of the RCA that is deleterious. Some examples of deleterious material are asphalt, brick, glass, wood chips, and wire. These materials will negatively affect the properties of fresh concrete made with an RCA that includes them. The procedure followed to determine the amount of deleterious material was TxDOT standards TEX-221-F (2004) \& TEX-217-F (2011). The identification of deleterious material is conducted by the examination of a particle and seeing if there is a presence of cement paste as well as coarse and fine aggregate. Color can also be an indication of whether a particle is deleterious or not, such as brick or asphalt.

Table 1 displays the absorption, $\mathrm{SG}$, and $\mathrm{D}_{\mathrm{RCA}}$ values determined for each sample. For this subset, the presence of deleterious material is much lower in the Texas samples as opposed to the samples from the Northeast. When examining the entire database available to the research team, it was noted that $\mathrm{D}_{\mathrm{RCA}}$ was highly variable, ranging from $1.87 \%$ to $35.1 \%$, with no distinct trends based on geography.

Table 1. NA and RCA Properties

\begin{tabular}{|c|c|c|c|c|c|c|c|}
\hline $\begin{array}{c}\text { State of } \\
\text { Origin }\end{array}$ & Sample & Type & Absorption & $\begin{array}{c}\text { Bulk } \\
\text { SG }\end{array}$ & Bulk SSD & $\begin{array}{c}\text { Apparent } \\
\text { SG }\end{array}$ & D $_{\text {RCA }}(\%)$ \\
\hline NJ & TIL & RCA & 5.41 & 2.31 & 2.43 & 2.64 & 4.63 \\
\hline PA & CCF & RCA & 5.01 & 2.33 & 2.45 & 2.64 & 5.95 \\
\hline PA & CCN & RCA & 5.02 & 2.33 & 2.44 & 2.63 & 10.33 \\
\hline TX & BCB & RCA & 5.95 & 2.28 & 2.42 & 2.64 & 2.29 \\
\hline TX & BCL & RCA & 5.52 & 2.29 & 2.42 & 2.62 & 2.96 \\
\hline TX & PG & NA & 1.83 & 2.55 & 2.60 & 2.68 & N/A \\
\hline TX & Sand & NA & 1.00 & 2.62 & 2.65 & 2.69 & N/A \\
\hline
\end{tabular}

Figures 3(a) - 3(c) shows some of the relationships among these parameters for nearly the full data set of the research team - the samples from the Southwest have not been completed and are not included. Figure 3(a) shows that there is a noisy inverse relationship between the deleterious content and absorption. This was unexpected. Figure 3(b) shows that there is only a weak relationship between the specific gravity of RCA and the amount of deleterious material it contains - one might expect a stronger one since most (i.e. brick and asphalt) deleterious materials have low specific gravity. Figure 3(c) shows that there is a strong linear relationship between the absorption of RCA and its specific gravity - a useful finding for mix designers. 

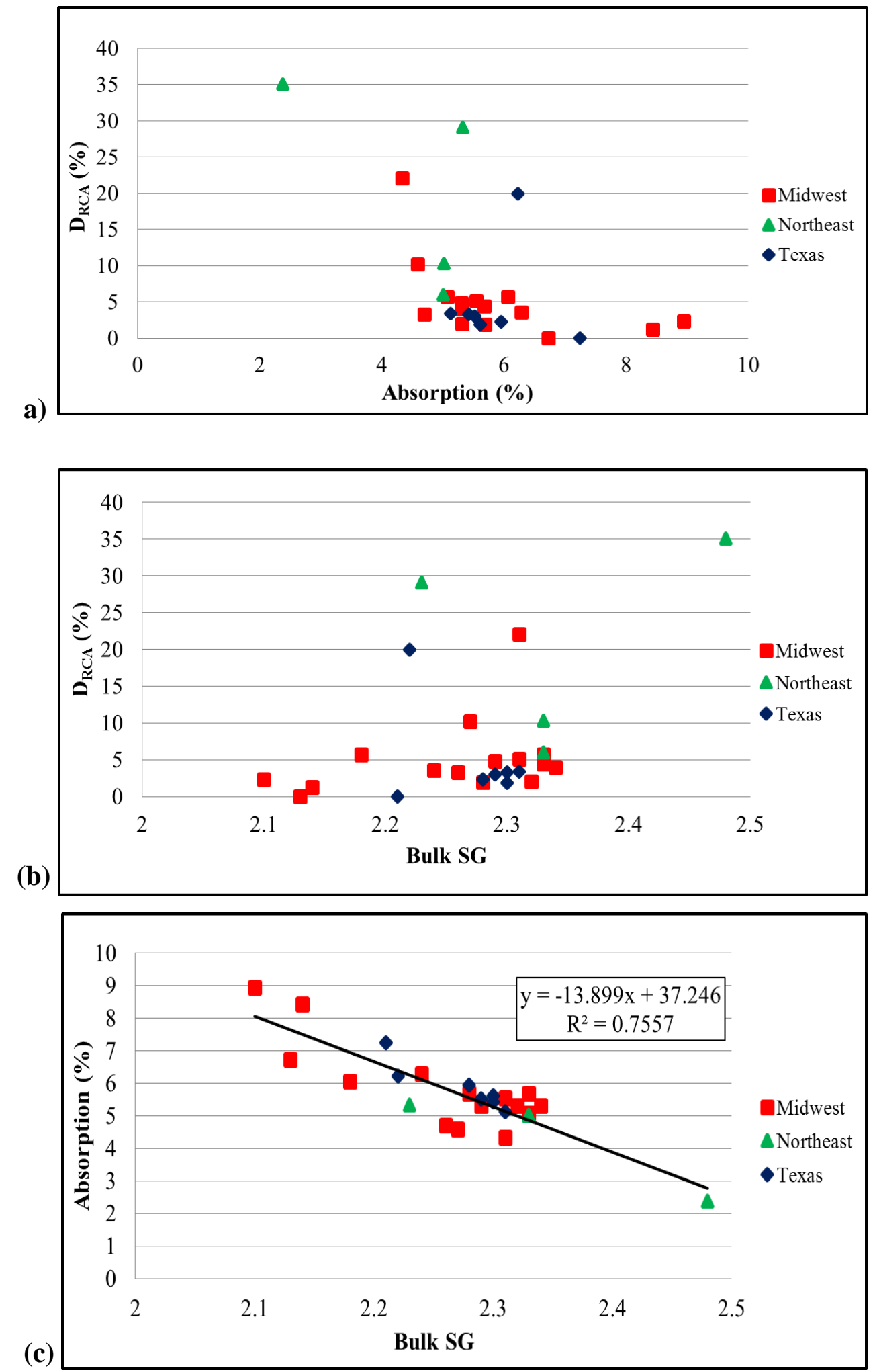

Figure 3. Relationship of RCA properties: a) DrCA vs Absorption, (b) DRCA vs Bulk SG, (c) Absorption vs Bulk SG 


\section{FRESH CONCRETE MIX DESIGN}

The design mix is referred to as a PG M1 Mix. The coarse aggregate is graded to that of the Pea Gravel Gradation, shown in Figure 1, and the mix is considered to be a normal strength mix, with a target compressive strength of 6000 psi. The target air content is $6 \%$, and target water cement ratio is 0.44 . The only admixture that was used for this mix design is PS 1466, a high range water reducing admixture, which can improve strength development as well as improve finishability and surface appearance. The target dosage for an M1 Mix is 6 oz./cwt. of PS 1466. The cement that was used was Portland Cement Type I/II; with an assumed SG of 3.15.

For these mixes, RCA will replace Natural Coarse Aggregate not by weight, rather volume. This method is called The Direct Volume Replacement Method (DVR). DVR takes a given volume of Coarse Natural Aggregate and replaces it with an equal volume of RCA. This allows for the total amount by volume of coarse aggregate (CA), fine aggregate (FA), cement, and water to remain consistent from mix to mix. This allows there to be little loss in the workability of the RCA concrete, given the absorption of the RCA is incorporated into the mix design. The three replacement percentages that were used for the mixes were $0 \%$ RCA, 50\% RCA, and 100\% RCA. Table 2 displays the amount of PS 1466, Cement, CA, FA, and water for each mix. The weights for the coarse and fine aggregate are all saturated surface dry (SSD) weights, which eliminate the need to account for the absorption of the aggregate. Each mix was adjusted to account for mortar loss-the weight of mortar (cement, water, and sand) predicted to be lost to the mixer sides.

Table 2. PG M1 Mixes

\begin{tabular}{|c|c|c|c|c|c|c|c|}
\hline Sample & $\begin{array}{c}\text { Replacement } \\
(\%)\end{array}$ & $\begin{array}{c}\text { PS } \\
1466 \\
(\mathrm{~mL})\end{array}$ & $\begin{array}{c}\text { Cement } \\
(\text { lbs. })\end{array}$ & $\begin{array}{c}\text { CA } \\
\text { Added } \\
(\mathrm{lbs} .)\end{array}$ & $\begin{array}{c}\text { FA } \\
\text { Added } \\
(\text { lbs. })\end{array}$ & $\begin{array}{c}\text { Water } \\
\text { Added (lbs.) }\end{array}$ & $\begin{array}{c}\text { Weight in } \\
\text { Mixer (lbs.) }\end{array}$ \\
\hline PG & 0 & 7.79 & 4.40 & 11.80 & 9.96 & 0.553 & 26.7 \\
\hline \multirow{2}{*}{ BCB } & 50 & 7.89 & 4.45 & 12.30 & 9.94 & 0.000 & 26.7 \\
\cline { 2 - 8 } & 100 & 7.99 & 4.51 & 12.02 & 10.11 & 0.098 & 26.7 \\
\hline \multirow{2}{*}{ BCL } & 50 & 7.89 & 4.44 & 11.90 & 10.10 & 0.260 & 26.7 \\
\cline { 2 - 8 } & 100 & 7.99 & 4.51 & 11.85 & 10.25 & 0.093 & 26.7 \\
\hline \multirow{2}{*}{ TIL } & 50 & 7.89 & 4.45 & 11.80 & 10.15 & 0.30 & 26.7 \\
\cline { 2 - 8 } CCN & 100 & 7.99 & 4.50 & 11.90 & 10.25 & 0.049 & 26.7 \\
\cline { 2 - 8 } & 100 & 7.99 & 4.50 & 12.07 & 10.04 & 0.106 & 26.7 \\
\hline CCF & 50 & 7.89 & 4.44 & 11.86 & 10.05 & 0.357 & 26.7 \\
\cline { 2 - 8 } & 100 & 7.99 & 4.49 & 11.85 & 10.20 & 0.159 & 26.7 \\
\hline
\end{tabular}

\section{DESIGN PROCEDURE}

A 0.5 -HP cement mixer was used with the following mixing procedure:

1. Place Saturated surface dry fine \& coarse aggregate, PS 1466, and water into the mixer 
2. Run the mixer for three minutes

3. Stop momentarily to add cement

4. Run the mixer again for three minutes

5. Stop the mixer then place a moist towel over drum to avoid any drying in the mix for three minutes

6. Run the mixer for two more minutes

7. Remove concrete from the drum, then weigh the yield

\section{COMPRESSIVE STRENGTH}

The cylinders were removed from the molds after 24 hours and placed into a curing tub, then were left in the tub for 27 days. On the $28^{\text {th }}$ day, the cylinders were removed from the tub, wiped with a paper towel then subjected to compressive testing following ASTM C49. Based on an initial subset of the overall project RCA sample data (16 samples from the Midwest), EQ. 1was developed to estimate the compressive strength for RCA mixes by taking into account Absorption for NA ( $\left.A_{n a}\right)$ and RCA (A), $D_{\text {RCA }}$ (D), and Replacement Percentage (R). $\beta_{f 1}, \beta_{f 2}, \quad \beta_{f 3}$, and $\beta_{f 4}$ are regression coefficients previously developed (Knaack et al 2013) shown in Table 3.

Table 3. Compressive Strength Regression Coefficients and Statistics

\begin{tabular}{|c|c|c|c|c|c|}
\hline \multirow{4}{*}{$\begin{array}{c}\text { Mean Value of } \\
\text { Unnormalized } \\
\text { Regression } \\
\text { Coefficients }\end{array}$} & $\beta f_{1}$ & 1.0241 & \multirow{4}{*}{$\begin{array}{l}\text { 95\% Confidence } \\
\text { Interval For } \\
\text { Unnormalized } \\
\text { Regression } \\
\text { Coefficients }\end{array}$} & $\beta f_{1}$ & {$[1.0026,1.0456]$} \\
\hline & $\beta f_{2}$ & -0.0241 & & $\beta f_{2}$ & {$[-0.0300,-0.0182$} \\
\hline & $\beta f_{3}$ & -0.0138 & & $\beta f_{3}$ & $\begin{array}{c}{[-0.0172,-} \\
0.0104]\end{array}$ \\
\hline & $\beta f_{4}$ & 0.0769 & & $\beta f_{4}$ & {$[0.0299,0.1239]$} \\
\hline
\end{tabular}

$$
\frac{f^{\prime}{ }_{c, R C A}}{f^{\prime}{ }_{c, N A}}=\beta_{f 1}+\beta_{f 2} \times \frac{A}{A_{n a}}+\beta_{f 3} \times \mathrm{D}+\beta_{f 4} \times \mathrm{R}
$$

Figure 4(a) displays the compressive strength of the five samples' (CCN, CCF, BCL, BCB and TIL) as well as the theoretical values using eq. 1. Figure 4(b) and 4(c) displays BCB's and CCN's compressive strength and its relationship with EQ.1, and show the 95\% confidence interval based on the regressed relationship of EQ.1. The $95 \%$ confidence intervals for the other mixes were similar, with some capturing the experimental results and some not. Table 4 presents the percent difference between the theoretical strength versus the actual strengths for the samples at 50\% and $100 \%$. Potentially important parameters that could not be directly included in the regression model are the surface texture, angularity, porosity, stiffness, and strength of the aggregates as well as the properties of the Interfacial Transition Zone (ITZ). Furthermore, given the generally small effect of RCA on the concrete strength (as compared to the stiffness), it is possible that any small variation between the actual cylinders properties and the mix design Properties (e.g., specific gravity, absorption, batch weights, inherent variation between cylinders of the same mix) could be a cause of increased variance (Knaack and Kurama et al 2013). 
(a)

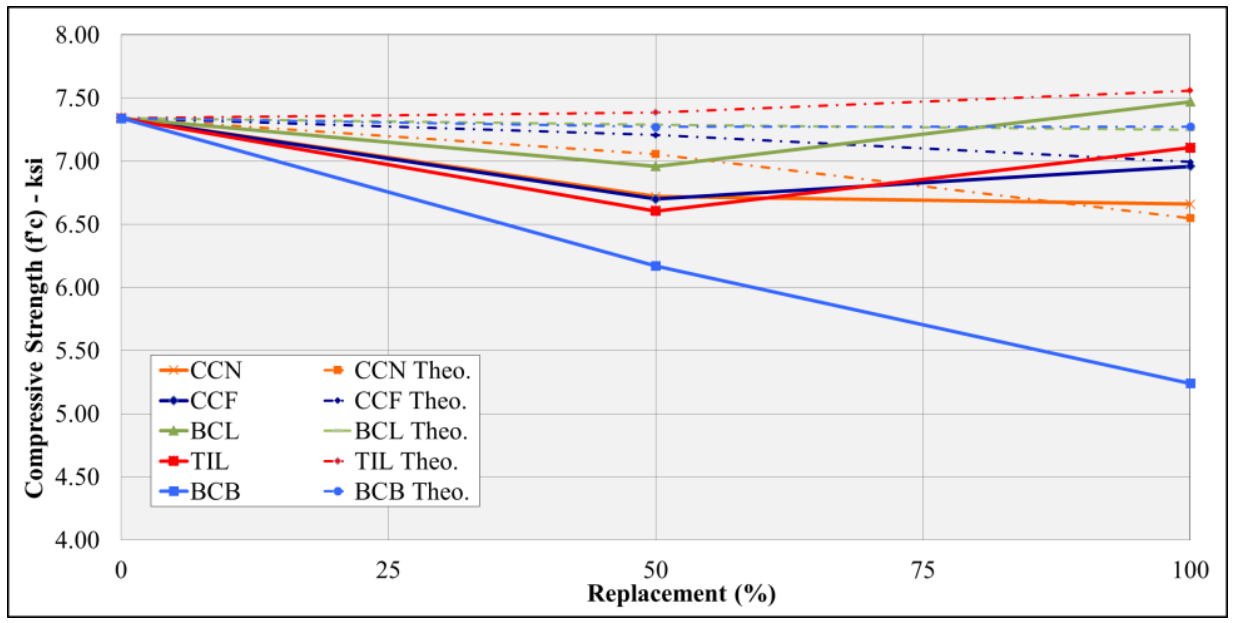

(b)

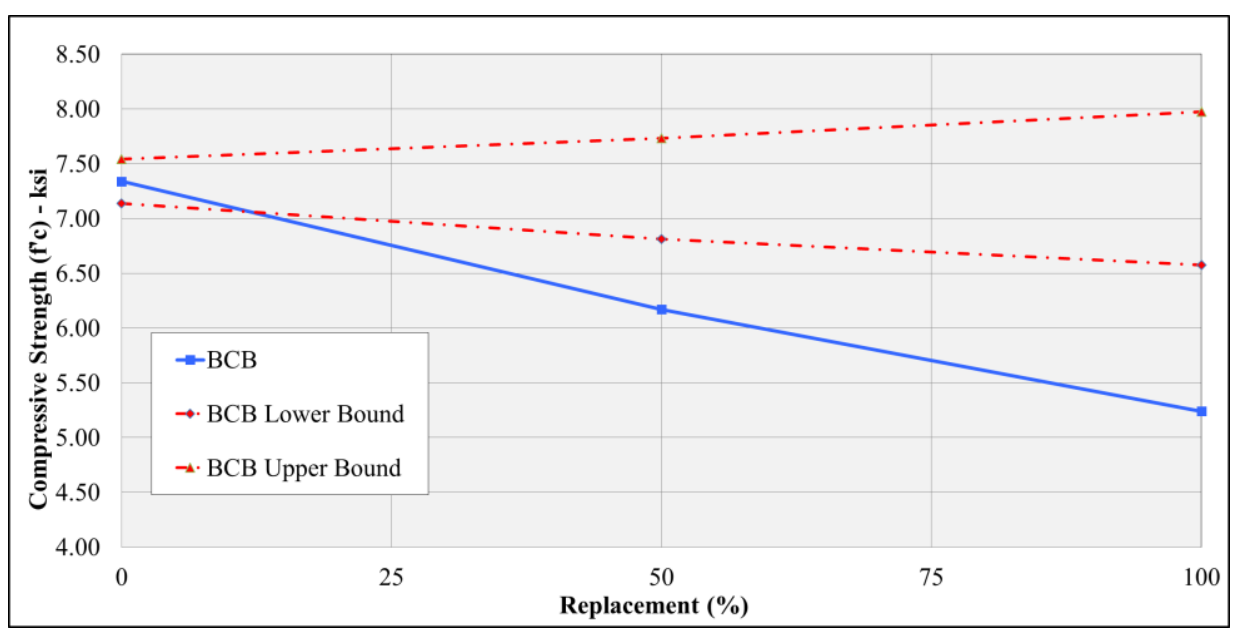

(c)

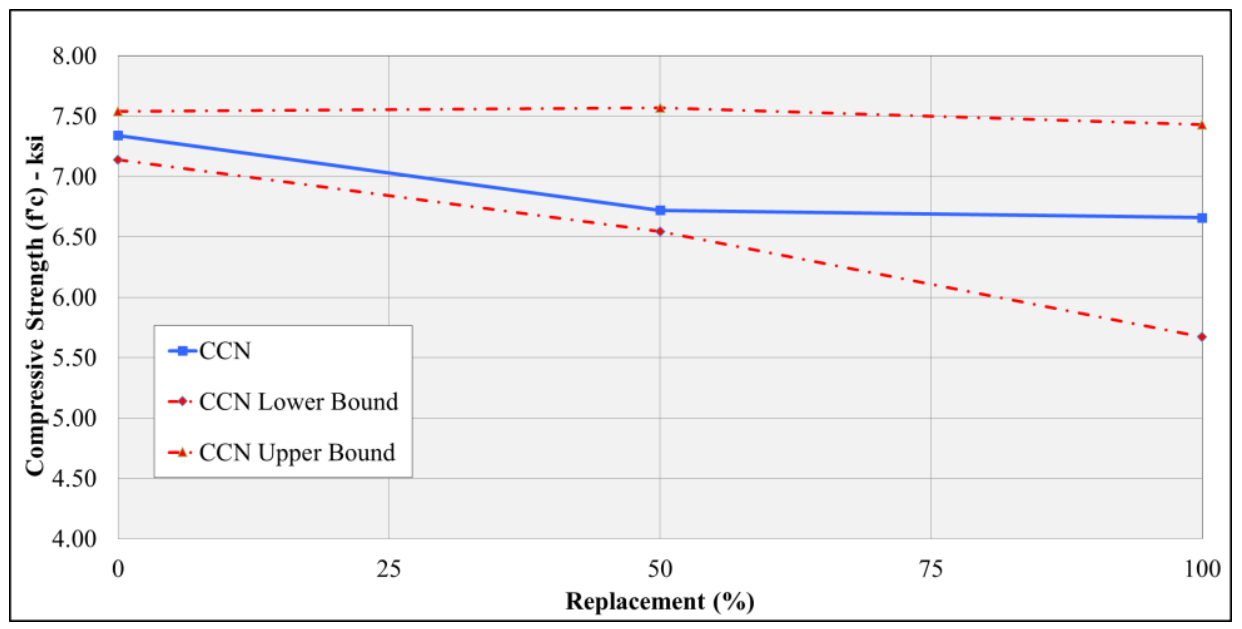

Figure 4 Relationship between Theoretical Values and Measured Values: (a) Compressive Strength for PG M1 Mixes, (b) 95\% Confidence Intervals for BCB, (c) $95 \%$ Confidence Intervals for $\mathbf{C C N}$ 
Table 4. Measured Values vs. Theoretical Values

\begin{tabular}{|c|c|c|c|c|c|c|c|c|}
\hline Sample & $\begin{array}{c}\text { Measured } \\
\mathrm{f}^{\prime} \mathrm{at} 50 \% \\
\mathrm{R}(\mathrm{ksi})\end{array}$ & $\begin{array}{c}\text { Theoretical } \\
\mathrm{f}^{\prime} \mathrm{c} \text { at 50\% } \\
\mathrm{R}(\mathrm{ksi})\end{array}$ & $\begin{array}{c}\text { Percent } \\
\text { Difference } \\
(\%)\end{array}$ & $\begin{array}{c}\text { Measured } \\
\text { f'c at } \\
100 \% \mathrm{R} \\
(\mathrm{ksi})\end{array}$ & $\begin{array}{c}\text { Theoretical } \\
\mathrm{f}^{\prime} \mathrm{c} \text { at 100\% } \\
\mathrm{R}(\mathrm{ksi})\end{array}$ & $\begin{array}{c}\text { Percent } \\
\text { Difference } \\
(\%)\end{array}$ & $\begin{array}{c}\text { Percent } \\
\text { Difference } \\
\text { from 0 to } \\
50 \%\end{array}$ & $\begin{array}{c}\text { Percent } \\
\text { Difference } \\
\text { from 0 to } \\
100 \%\end{array}$ \\
\hline BCB & 6.17 & 7.27 & 16.39 & 5.24 & 7.27 & 32.5 & -17.32 & -33.4 \\
\hline BCL & 6.96 & 7.29 & 4.59 & 7.47 & 7.25 & 3.00 & -5.31 & 1.80 \\
\hline CCF & 6.70 & 7.21 & 7.30 & 6.96 & 6.99 & 0.50 & -9.12 & -5.3 \\
\hline CCN & 6.72 & 7.06 & 4.88 & 6.66 & 6.55 & 1.70 & -8.82 & -9.71 \\
\hline TIL & 6.61 & 7.39 & 11.2 & 7.11 & 7.56 & 6.17 & -10.53 & -3.24 \\
\hline
\end{tabular}

Figure 4 shows that EQ 1, that was developed using only the Midwest project samples, cannot accurately predict the compressive strength of the mixes described herein, which included RCA from Texas and the Northeast. The values in Table 4 shows that the theoretical values were much closer for $50 \%$ replacements rather than $100 \%$, which could be a result of the change of absorption from NA to RCA as well as the increased amount of $\mathrm{D}_{\mathrm{RCA}}$. From these evaluations, it can be concluded that further testing and evaluation of other samples are needed to refine the previously developed prediction model.

\section{CONCLUSION}

The following conclusions are made:

1. Quality concrete can be made with RCA following the DVR method. The strengths of the mixes with $50 \%$ RCA replacement differed from their NA counterparts by approximately $\pm 20 \%$; for $100 \%$ RCA replacement the difference was $\pm 35 \%$.

2. A model created to predict the strength of RCA concrete mixes based on the absorption and DCRA of a subset of all available data needs further development - this is future work planned by the project team.

3. The variability of RCA properties available for purchase was reasonably large for gradation (many sold as road base or for other applications other than concrete making) and for deleterious material (with ranging from $1.87 \%$ to $35.1 \%$ over the data set studied).

4. The specific gravity of the RCA samples was also variable ranging from 2.1 to 2.5

5. The absorption of the RCA data set ranged from approximately to $10 \%$, and it was linearly related to the RCA specific gravity.

\section{ACKNOWLEDGEMENTS}

This research is funded by the National Science Foundation (NSF) under Grant No. CMMI 1436758. The support of the NSF Program Directors, Drs. Y.G. Hsuan and K.I. Mehta, is gratefully acknowledged. Any opinions, findings, conclusions, and/or recommendations in the paper are those of the authors and do not necessarily represent the views of the NSF or the program directors acknowledged. Additionally, we wish to thank all the recycled concrete operations that supported this study by donating and sharing insights with researchers. Additionally, we would like to give a special thanks to Owen Sanderson and ETTL for providing access to their testing facilities. Finally, assistance provided by all natural aggregate producers 
was greatly appreciated, and the project could not have been completed if it were not for these individuals.

\section{REFERENCES}

ACI Committee 555 (2001) "Removal and Reuse of Hardened Concrete," American Concrete Institute, Farmington Hills, MI.

ASTM C 33 (2013). “Standard Specification for Concrete Aggregates.” ASTM International, West Conshohocken, PA, 11 pages.

ASTM C 127 (2013) “Standard Test Method for Density Relative Density (Specific Gravity) \& Absorption of Coarse Aggregates" ASTM International, West Conshohocken, PA, 10 pages.

ASTM C 128 (2013). "Standard Test Method for Density Relative Density (Specific Gravity) \& Absorption of Coarse Aggregates." ASTM International, West Conshohocken, PA, 10 pages.

ASTM C 494/C 494M (2013). "Standard Specification for Chemical Admixtures for Concrete.” ASTM International, West Conshohocken, PA, 10 pages.

Davis, M. and McGinnis, M (2015). "Use of Recycled Concrete Aggregates (RCA) for Improved Sustainability of Reinforced Concrete Building Structures - Economic Considerations". American Society of Engineering Education Paper, University of Texas at Tyler, Tyler, Texas.

Davis, M. and McGinnis, M (2015). "Environmental Considerations of Recycled Concrete Aggregates (RCA) for Improved Sustainability of Reinforced Concrete Building Structures". Sustainable Construction Materials \& Technologies (SCMT4) Paper, University of Texas at Tyler, Tyler, Texas.

Davis, M. and McGinnis, M (2015). “Use of Recycled Concrete Aggregates (RCA) for Improved Sustainability of Reinforced Concrete Building Structures - Economic Considerations". American Society of Engineering Education Paper, University of Texas at Tyler, Tyler, Texas.

Knaack, A. and Kurama, Y., "Behavior of Reinforced Concrete Beams with Recycled Concrete Coarse Aggregates," J. of Structural Engineering, ASCE, Vol. 141, No. 3, March 2015. (DOI:10.1061/(ASCE)ST.1943-541X.0001118)

Knaack, A. and Kurama (May-June 2015) Y., "Creep and Shrinkage of Normal Strength Concrete with Recycled Concrete Aggregates,” ACI Materials J., American Concrete Institute, Vol. 112, No. 3, pp. 451-462.

Knaack, A. and Kurama, Y (September-October 2013), "Design of Normal Strength Concrete

Mixtures with Recycled Concrete Aggregates,” ACI Materials J., Vol. 110, No. 5pp. 483-493

Knaack, A. and Kurama, Y. (2013). "Sustainable Concrete Structures using Recycled Concrete Aggregate: Short-Term and Long-Term Behavior Considering Material Variability." Ph.D. Dissertation, University of Norte Dame, Norte Dame, Indiana

Knaack, A. and Kurama (September-October 2015) Y., "Sustained Service-Load Behavior of Concrete Beams with Recycled Concrete Aggregates," ACI Structural J., American Concrete Institute, Vol. 112, No. 5, September-October 2015, pp. 565-577.

Mehta, K. (October 2001), "Reducing the Environmental Impact of Concrete," Concrete International, American Concrete Institute, pp.61-66 
TEX-217 (2005). "Determining Deleterious Material And Decantation Test For Coarse Aggregates (Bituminous Mixtures)”. Texas Department of Transportation, TxDOT. 2011

TEX-221-F (2004). "Sampling Aggregate for Bituminous Mixtures, Surface Treatments and Limestone Rock Asphalt". Texas Department of Transportation, TxDOT. 2004 